\title{
Reply to the Letter: Increased bioavailability of plasma polyphenols via the intestinal fermentation of soybean fibers: a role for gut microbiome?
}

\author{
Aphichat Trakooncharoenvit ${ }^{1,3} \cdot$ Seiya Tanaka ${ }^{1} \cdot$ Erika Mizuta $^{1} \cdot$ Tohru Hira $^{1,2} \cdot$ Hiroshi Hara $^{1,2}$
}

Published online: 1 July 2019

○) Springer-Verlag GmbH Germany, part of Springer Nature 2019

\section{Dear Prof Salvatore Chirumbolo, $\mathrm{PhD}$}

First, we would like to thank you for your comments on our recent paper and the suggested references. We also agree that quercetin might act as a molecular ignition for gut microbiome to release such catabolites. From your suggestion and evidence, quercetin degraded products led to the formation of propionic and other organic acids [1]. However, we would like to add the explanation that quercetin catabolites are not the majority of the cecal organic acids when compared to organic acids produced from the fermentation of dietary fiber [2,3]. This statement is confirmed by our cecal organic acids result. Organic acid concentrations of Q group are lower than that of soybean fiber-treated (QS) group, especially propionic concentration [4]. This suggests that cecal organic acids were mainly caused by cecal fermentation of dietary fibers and not quercetin degradation. However, we have planned to perform another experiment by feeding rats with normal diet, or normal diet containing soybean fiber, or normal diet containing both soybean fiber and quercetin. Results from this experiment might give

This Reply to a Letter to the Editor refers to the original publication available here: https://doi.org/10.1007/s00394-01901992-9.

The letter to which this reply refers can be read here: https://doi. org/10.1007/s00394-019-02029-x.

Aphichat Trakooncharoenvit

p43sg333@hotmail.com

Hiroshi Hara

hara@chem.agr.hokudai.ac.jp

1 Graduate School of Agriculture, Hokkaido University, Sapporo 060-8589, Japan

2 Research Faculty of Agriculture, Hokkaido University, Sapporo 060-8589, Japan

3 Nutritional Biochemistry Laboratory, Hokkaido University, Sapporo, Japan us more evidence to explain the effect of this fiber on the enhancement in quercetin bioavailability.

You have mentioned the important role of gut microflora in quercetin metabolism and flavonol bioavailability in plasma. We hypothesized that cecal bacteria might have upregulated the expression of several genes related to carbohydrate-metabolizing enzymes, wherein the dietary fibers were used as a substrate during their growth [5-7]. Consequently, quercetin and its metabolites had evaded bacterial degradation and had elevated within plasma.

Upon your suggestion on Iglewics and Hoaglin's robust test for multiple outliers, we have performed it on our data according to the formulation from Iglewicz and Hoaglin's handbook [8]. No outliers were observed in the calculations on our raw data, so we can confirm that our data set could be used.

\section{References}

1. Kawabata K, Yoshioka Y, Terao J (2019) Role of intestinal microbiota in the bioavailability and physiological functions of dietary polyphenols. Molecules 24(2):370

2. Henningsson $\AA$, Björck I, Nyman M (2001) Short-chain fatty acid formation at fermentation of indigestible carbohydrates. Näringsforskning 45(1):165-168

3. Dhingra D, Michael M, Rajput H, Patil RT (2011) Dietary fibre in foods: a review. J Food Sci Technol 49(3):255-266

4. Trakooncharoenvit A, Tanaka S, Mizuta E et al (2019) Water-soluble dietary fibers enhance bioavailability of quercetin and a fiber derived from soybean is most effective after long-term feeding in rats. Eur J Nutr. https://doi.org/10.1007/s00394-019-01992-9

5. Hervert-Hernández D, Goñi I (2011) Dietary polyphenols and human gut microbiota: a review. Food Rev Int 27:154-169

6. Palafox-Carlos H, Ayala-Zavala JF, González-Aguilar GA (2011) The role of dietary fiber in the bioaccessibility and bioavailability of fruit and vegetable antioxidants. J Food Sci 15:76

7. Flint HJ, Scott KP, Duncan SH et al (2012) Microbial degradation of complex carbohydrates in the gut. Gut Microbes 3:289-306

8. Iglewicz B, Hoaglin DC (1993) How to detect and handle outliers. ASQC Quality Press, Milwaukee, Wisconsin 